\title{
Analysis and Modelling of Slope Failures in Municipal Solid Waste Dumps and Landfills: A Review
}

\author{
Abdullah Ansari*† and Prashant B. Daigavane** \\ * Department of Civil Engineering, Indian Institute of Technology, New Delhi-110016, India \\ **Department of Civil Engineering, Government College of Engineering, Nagpur-441108, India \\ †Corresponding author: Abdullah Ansari; ansariaa@civil.iitd.ac.in
}

Nat. Env. \& Poll. Tech.

Website: www.neptjournal.com

Received: $15-04-2020$

Revised: 26-05-2020

Accepted: 04-06-2020

Key Words:

Landfill

MSW

Modelling

Slope failures

Environment

\begin{abstract}
The essential issues solved by geoenvironmental engineers relate to the assurance of uncontaminated regions of the subsurface just as the remediation of locales of the subsurface that have been sullied by releasing waste materials, spilling over the ground and underground stockpiling tanks and penetration of pesticides. In city areas, garbage and waste materials are generally dumped into landfills. A landfill site, which is otherwise called a trash dump, is used for the disposal of waste materials by burial. A safe landfill is a deliberately built sorrow in the ground into which wastes are put. The principal objective is to stay away from any water driven association between the wastes and the surrounding environment especially groundwater. This paper discusses landfill, in terms of its construction, stability and failure. The analysis and modelling of the landfill failure occurred in different countries like Poland, Turkey, Israel, the Philippines, China and Sri Lanka which are discussed.
\end{abstract}

\section{INTRODUCTION}

The primary problems addressed by geoenvironmental engineers pertain to the protection of uncontaminated regions of the subsurface as well as the remediation of regions of the subsurface that have been contaminated by one or more events which involve industrial chemical spills, leaking waste containment facilities, leaking above-ground and underground storage tanks, and infiltration of pesticides.

A landfill site which is also known as a garbage dump or dumping ground is a site for the disposal of waste materials by burial. Some landfills are also used for waste management purposes, such as the temporary storage, consolidation and transfer, or processing of waste material. Processing of waste materials includes sorting, treatment and recycling. Unless they are stabilized, these areas may experience severe shaking or soil liquefaction of the ground in case of a large earthquake. A secure landfill is a carefully engineered depression in the ground into which wastes are put. The main objective is to avoid any hydraulic connection between the wastes and the surrounding environment particularly groundwater.

A landfill is a bathtub in the ground; a double-lined landfill is one bathtub inside another. Bathtubs leak two ways, one out the bottom and another over the top. An important feature in the identification and assessment of potential failure mode is the fact that both covers and liners for modern landfills are typically multilayer composites composed of both soil and geo-synthetic materials. The liner system contains several interfaces whose resistance against interface shear stresses may be low, and thus these act as possible failure surfaces. Additionally, all classical geotechnical failure modes are possible depending on site-specific conditions (usually involving saturated fine-grained soils) and the placement and geometry of the waste mass. Landfill failure can be studied by carrying out the analysis and modelling of failure surfaces. For these computational techniques, computer programs are used. This paper discusses landfill, in terms of its construction, stability and failure. The analysis and modelling of the landfill failure occurred in different countries like Poland, Turkey, Israel, the Philippines, China and Sri Lanka which are given in Table 1.

\section{ANALYSES OF LANDFILL SLOPE FAILURES}

Sarihan \& Stark (2008) carried out a back analysis of landfill failures and investigated the shear strength of municipal solid waste (MSW) using the techniques of back analyses for different slope failures associated with wastes across the world. Slope failure for landfills may be resulted due to heavy rainfall or the development of tension cracks. Sometimes it may be associated with the harmful effects of leachate. Leachate is a widely used term in the environmental 
Table 1: Historical record of slope failures in municipal solid waste dumps and landfills.

\begin{tabular}{|llll|}
\hline Year & Location & Failure Reason & Reference \\
\hline 1965 & Warsaw, Poland & Steep slopes, excessive leachate level & Bouzza \& Wojnarowicz 2000 \\
1988 & California, USA & Sliding along interfaces within the composite liner system & Mitchell et al. 1990 \\
1993 & Istanbul, Turkey & Heavy rains, excessive leachate level & Kocasoy \& Curi 1995 \\
1996 & Cincinnati, Ohio, USA & Softening of underlying native soils & Stark et al. 2000 \\
1996 & Mahoning, Ohio, USA & Failure along wet bentonite layer of the unreinforced GCL & Stark et al. 1998 \\
1997 & Hiriya, Israel & Steep slopes, lack of drainage controls, high moisture content & Huvaj-Sarihan \& Stark 2008 \\
2000 & Payatas, Manila, Philippines & Failure along MSW and clay subsoil induced by heavy rains & Huvaj-Sarihan \& Stark 2008 \\
2005 & Bandung, Indonesia & High water pressure in the soft subsoil & Koelsch et al. 2005 \\
2008 & Shenzhen, China & High water level within landfill & Peng et al. 2016 \\
\hline
\end{tabular}

sciences where it has the specific meaning of a liquid that has dissolved or entrained environmentally harmful substances that may then enter the environment. It is most commonly used in the context of land-filling of putrescible or industrial waste. An investigation found that the landfill doesn't have an engineered bottom liner, final cover or leachate and gas control systems. Analysis of failure slopes of Gnojna Grora landfill in Poland, Istanbul Landfill in Turkey, Hiriya Landfill in Israel, and Payatas Landfill in the Philippines are discussed below.

\section{Gnojna Grora Landfill in Poland}

Bouzza \& Wojnarowicz (2000), described the Gnojna Grora Hill landfill, in Warsaw, Poland. The archaeological work performed for this landfill revealed that the landfill dates to the 14th century which showed that it is an old landfill without any liner or cover system layers. In 1965, cracks were observed in nearby buildings due to the movements in the landfill which showed that fill is composed of large amounts of demolition debris composed of old domestic MSW. The unit weight of the waste material was estimated to be $17 \mathrm{kN} / \mathrm{m}^{3}$ as the waste is mixed with demolition debris. Groundwater or leachate level was found to be 3 to 5 meters below the ground surface based on piezometer records (Fig. 1a).

To back-calculate, the Municipal Solid Waste (MSW) was assumed to exhibit a cohesion intercept (c') of $0 \mathrm{kPa}$ and the back-calculated friction angle $\left(\varphi^{\prime}\right)$ is $21^{\circ}$. They estimated that the average effective normal stress and corresponding back-calculated shear strength on the observed failure surface through the waste are $106 \mathrm{kPa}$ and $40.7 \mathrm{kPa}$ respectively. The shear strength of MSW decreases with age (Siegel et al. 1990, Brandl 1998, Gabr et al. 2002, Reddy \& Bogner 2003). So it is acceptable to assume cohesion intercept is equal to 0 for a 300 years old MSW demolition debris mix and back-calculate the friction angle.

\section{Istanbul Landfill in Turkey}

This landfill of Turkey described by Kocasoy \& Curi (1995) and Koerner \& Soong (2000) which is about $30 \mathrm{~km}$ away from the city centre in Istanbul (Turkey), operated since 1976. Their study showed that maximum MSW slope height was about $45 \mathrm{~m}$, with steep front slopes of up to 45 degrees or even more and MSW was placed without any liner system. Waste in this landfill was not compacted and not covered with soil. Landfill failure occurred on April 28, 1993, and resulted in 27 casualties and involved approximately 500,000 $\mathrm{m}^{3}$ to more than $1,000,000 \mathrm{~m}^{3}$ of waste. Fires were known to be burning on the surface of the waste at several places during most of the year before the slide which is shown in Fig. 1b reported by Kocasoy \& Curi (1995).

In this case, the explosion could not have been the main cause of the movement of the waste. They also confirmed that the heavy rains, and excessive leachate level built up within the old decomposed waste caused by water infiltrating
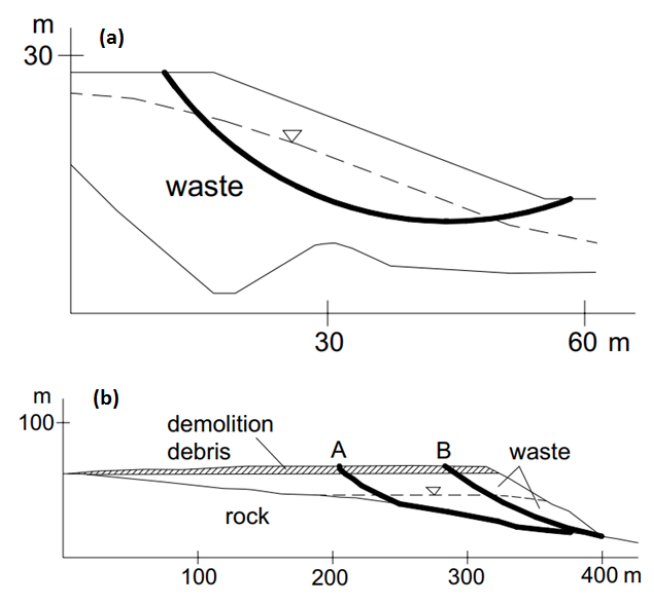

Fig. 1: Approximate slope profile of (a) Gnojna Grora Landfill (Poland) (b) Istanbul Landfill (Turkey). 

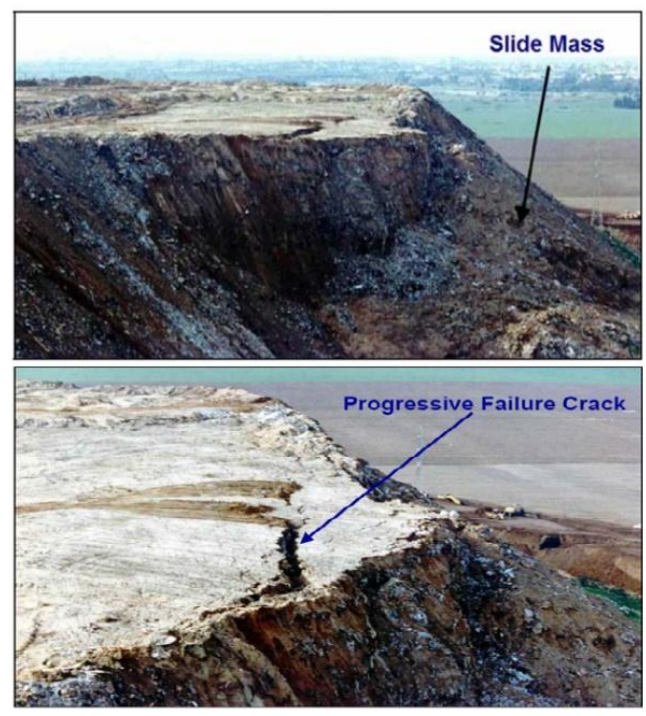

Fig. 2: Failure of Hiriya Landfill (Israel).

from the adjacent surface water ponds were likely the triggering mechanism, together with recently placed demolition debris on top of the waste. As shown in Fig. 1b, the waste mass there is impermeable rock. The authors assumed the unit weight of $11 \mathrm{kN} / \mathrm{m}^{3}$ because no further information is available. It is assumed that the failure surface is the most reliable because it is based on their observations at the site and data they obtained from the municipality of Istanbul. A and $\mathrm{B}$ represent the non-circular and circular failure surface respectively.

\section{Hiriya Landfill in Israel}

The Hiriya landfill in Israel failed in 1997 due to steep slopes, lack of drainage controls and high moisture content which is located east of Tel-Aviv which is an open area at the convergence of the Shappirim River and the Ayalon River (Fig. 2). Isenberg et al. (2004) investigated that the dump has been used for the disposal of MSW for the greater TelAviv area for decades. They also confirmed that the landfill does not have an engineered bottom liner, cover and gas control systems.

\section{Prayatas Landfill in Philippines}

The Prayatas Landfill is located in the NE part of Manila. It has been in operation since 1973 and about 1500 tonnes of MSW are placed since 1996. The exact mechanism of failure is not known but several factors like heavy rainfall may lead to cause saturation of MSW and water ponding on top of the slopes were reported by Merry et al. (2005).

\section{MODELING OF LANDFILL SLOPE FAILURES}

\section{Guangming Landfill at Shenzhen, China}

Ouyang et al. (2017) studied catastrophic landslide of the construction waste landfill at Guangming, Shenzhen, China
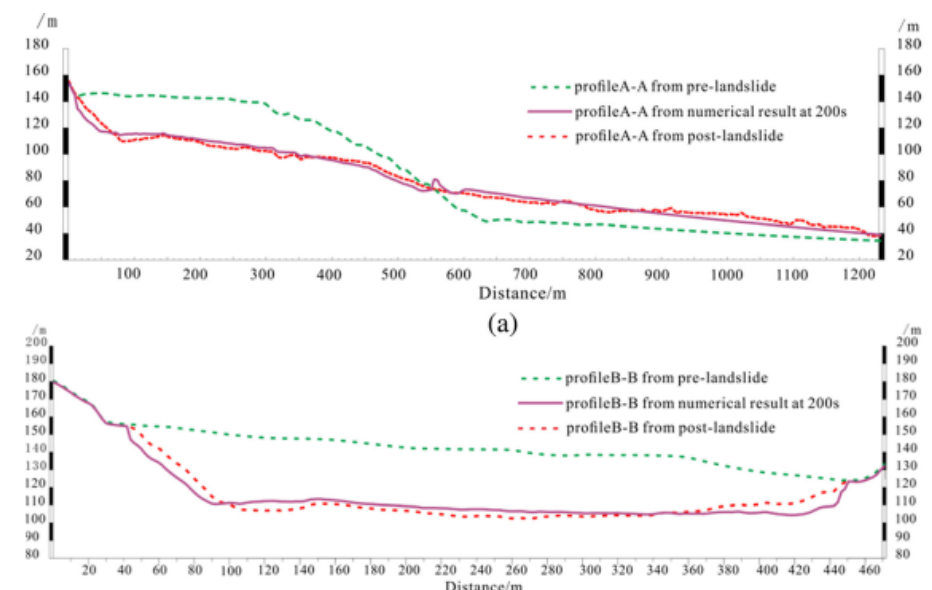

(b)

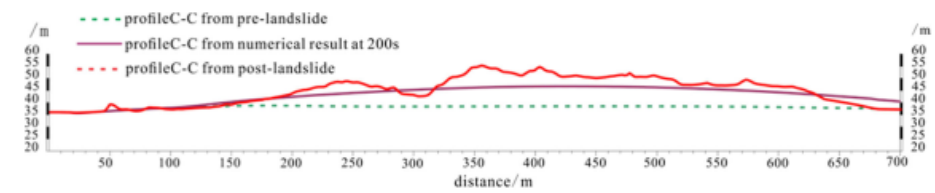

(c)

Fig. 3: Comparison of numerical results and field investigation results along (a) the main sliding profile A-A, (b) transverse profile B-B, and (c) transverse profile C-C for Guangming landfill at Shenzhen, China (Ouyang et al. 2017). 
occurred in December 2015 which destroyed 33 buildings and caused 69 deaths (Yin et al. 2016). This type of landfill occurred without the involvement of rainfall or heavy rainfall with $\mathrm{H}=111 \mathrm{~m}$ and $\mathrm{L}=1.2 \mathrm{~km}$. The mesh-free Smooth Particle Hydrodynamics ( $\mathrm{SPH})$ method is applied in modelling the landslide over natural terrain.

Investigation for this landslide showed that the soil is almost fully liquefied in the sliding surface due to plenty of water. Thus, it is highly possible that plenty of water was stored in the waste fill. Unmanned Aerial Vehicle (UAV) used to collect the pictures two days before the event and three days after the event. Snapshots of the computed flow height were collected at different time intervals. Graphs were plotted in which the author compared the profile before and after the landslide event (Fig. 3).

Liang et al. (2019) studied the Shenzhen landslide based on dynamic simulation using Smooth Particle Hydrodynamics (SPH) modelling considering dilatancy effects. As shown in the Fig. 4, the most obvious feature of the landslide was that its travelling distance exceeded $1.2 \mathrm{~km}$ and the landslide mobility index equal to 0.092 was much lower than that of a general landslide. A landslide mobility index lower than 0.3 denotes high mobility. The Dilatancy model describes the interaction between the fluid and solid phases. The key role of these dilatancy models is the combination of the dilation and contraction behaviours with the equilibrium solid volume fraction, which is related to the solid volume fraction and effective stress. The grid or mesh-based methods have been widely applied in various areas of computational fluid dynamics and computational solid mechanics (Anderson \& Wendt 1995, Fung \& Tong 2001).

However, the existence of the grid or mesh can cause various difficulties in solving problems related to the free surface, extremely large deformations, a deformable boundary, and a moving interface (Liu \& Liu 2010). Mesh-free methods have been developed in the recent past (Liu \& Gu 2005), and SPH methods, which were invented to solve astrophysical problems, have been widely applied in many fields (Lucy 1977, Liu \& Liu 2003, Violeau 2012). The soil on the sliding surface was liquefied (Ouyang et al. 2016), and the bottom of the deposited body exerted excess pore water pressure.

\section{Udapalatha Municipal Landfill at Udapalatha, Sri Lanka}

Prathapan et al. (2015) carried out the modelling of Udapalatha Municipal landfill (Sri Lanka) to discuss the spatial variation of shear strength and consolidation characteristics. Chances of slope failure of a landfill can
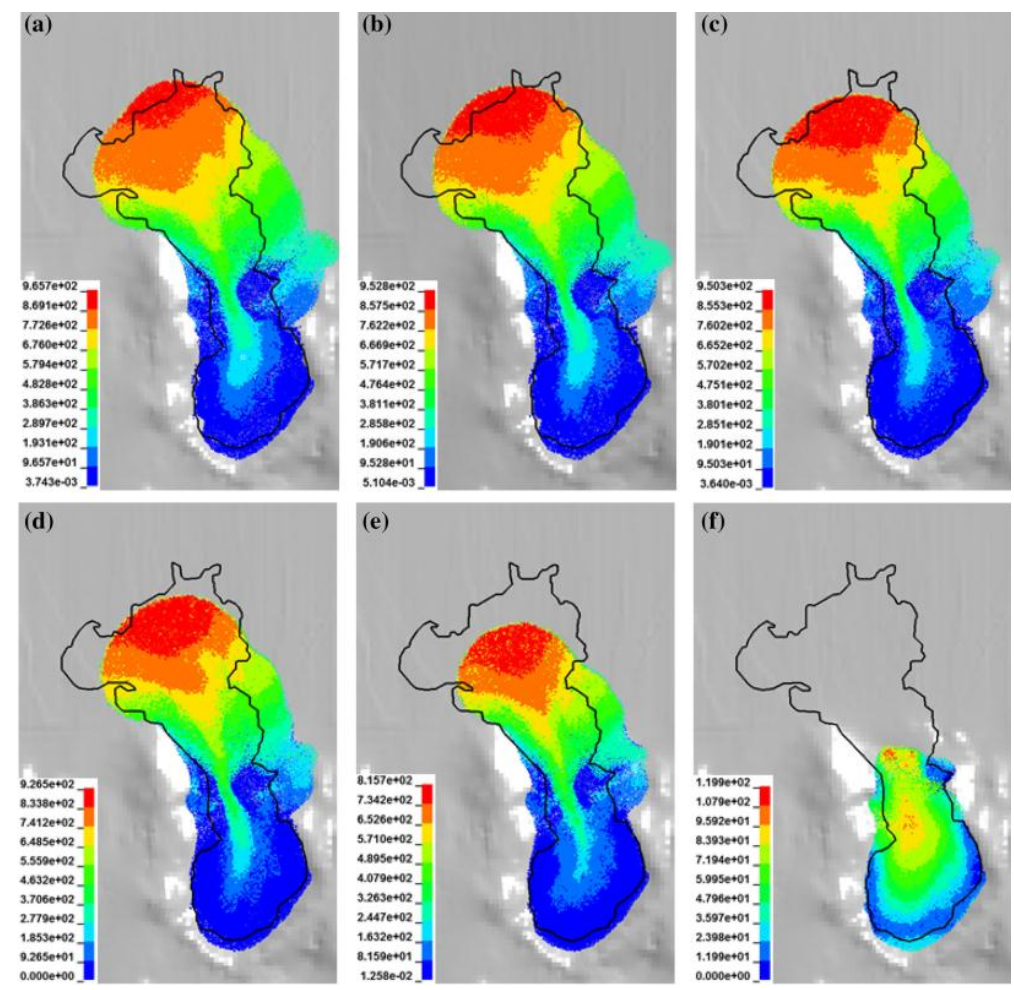

Fig. 4: Modelling output in terms of deposition area and displacements of different solid volume fractions at $\mathrm{t}=200 \mathrm{~s}$ for $(\mathrm{a}) \mathrm{m}_{0}=0.57$; $(\mathrm{b}) \mathrm{m}_{0}=0.59$; (c) $\mathrm{m}_{0}=0.61 ;$ (d) $\mathrm{m}_{0}=0.62 ;$ (e) $\mathrm{m}_{0}=0.63$; and (f) $\mathrm{m}_{0}=0.64$ (Liang et al. 2019). 


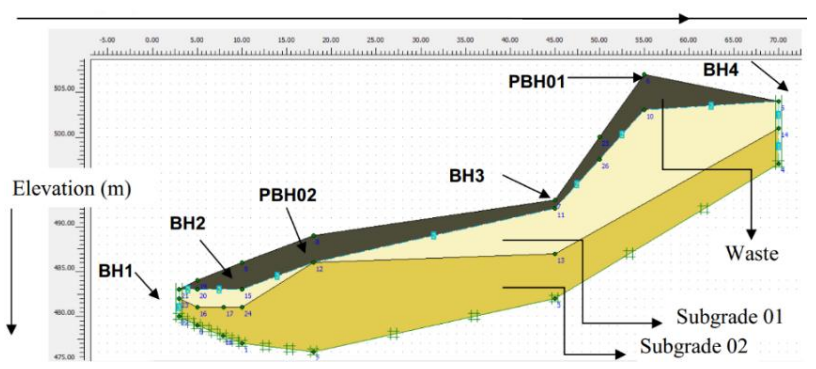

Fig. 5: Modelling of Cross-section of new site and locations of boreholes.

Table 2: Shear strength and consolidation parameters (Prathapan et al. 2015).

\begin{tabular}{|lllll|}
\hline \multirow{2}{*}{ Location } & \multicolumn{2}{l|}{ Shear strength parameters } & \multicolumn{2}{l|}{ Consolidation parameters } \\
\cline { 2 - 5 } & $\mathrm{c}^{\prime}(\mathrm{kPa})$ & $\varphi^{\prime}$ (degree) & $\kappa^{*}$ & $\lambda^{*}$ \\
\hline BH 02 & 46.7 & 19.8 & 0.0020 & 0.0616 \\
PBH 02 & 50.2 & 14.0 & 0.0021 & 0.0707 \\
PBH 01 & 15.4 & 31.8 & 0.0056 & 0.0790 \\
\hline
\end{tabular}

occur during the construction of the landfill or after the closure of the landfill.

The shear strength and consolidation were determined using direct shear and Oedometer tests. Stability is measured in terms of the factors of safety, which can be evaluated using SLOPE/W and PLAXIS 2D software considering both homogeneities as well as the heterogeneity of the material properties. The above analysis yielded critical factors of safety ranging between
1.18 and 1.72 in Slope/W and 1.14 and 1.43 in PLAXIS 2D when heterogeneous properties were used in separate analyses assuming homogeneity (Fig. 5). However, by considering spatial variation, the factor of safety was found to be 1.62 and 1.32 in SLOPE/W and PLAXIS 2D analyses respectively, emphasizing the importance of considering the spatial variation of shear strength properties in stability analyses.

The parameters for PLAXIS 2D analysis are effective cohesion $\left(c^{\prime}\right)$, effective friction angle $\left(\varphi^{\prime}\right)$, modified compression index $\left(\lambda^{*}\right)$, modified swelling index $\left(\kappa^{*}\right)$, modified creep index $\left(\mu^{*}\right)$ and unit weight $(\gamma)$. While, on another hand, the input parameters for SLOPE/W software are effective cohesion $\left(c^{\prime}\right)$, effective friction angle $\left(\varphi^{\prime}\right)$ and unit weight $(\gamma)$. Results for both the direct shear test and consolidation shear test at three different locations are given in Table 2. Cross-section of the landfill modelled by both PLAXIS 2D and SLOPE/W for calculating the Factor of Safety (FOS) which is shown in the Figs. $6 \& 7$. The estimated value of FOS using both the methods is also mentioned in Table 3.

Based on the analyses carried out considering uniform as well as spatial variations of properties, the following conclusions are made.

(a) Both shear strength, as well as consolidation parameters, showed considerable variation within the landfill.

(b) The range of values of FOS obtained corresponding to the uniform variation of lowest and highest values of effective cohesion were significant.

Table 3: Summary of the factor of safety values (Prathapan et al. 2015).

\begin{tabular}{|llllll|}
\hline Analysis Method & & Cohesion $(\mathrm{kPa})$ & Friction Angle (degree) & \multicolumn{2}{l|}{ Factor of Safety } \\
\cline { 5 - 6 } & & & - & SLOPE/W & PALXIS 2D \\
\hline Spatial Variation & - & - & 31.8 & 1.618 & 1.319 \\
Uniform & PBH 01 & 15.4 & 19.8 & 1.184 & 1.139 \\
& BH 02 & 46.7 & 14.0 & 1.594 & 1.382 \\
& PBH 02 & 50.2 & & 1.722 & 1.428 \\
\hline
\end{tabular}

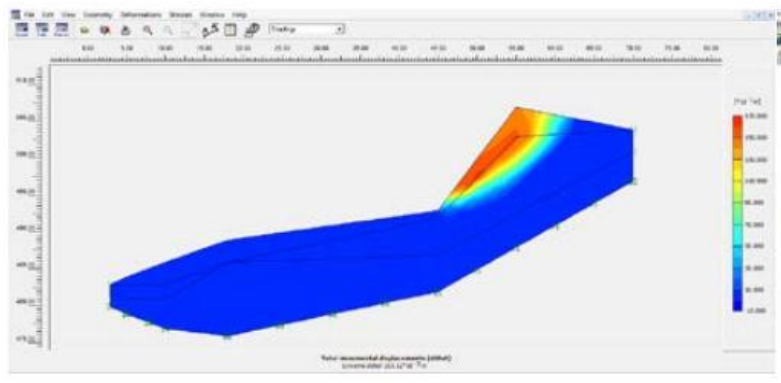

(a)

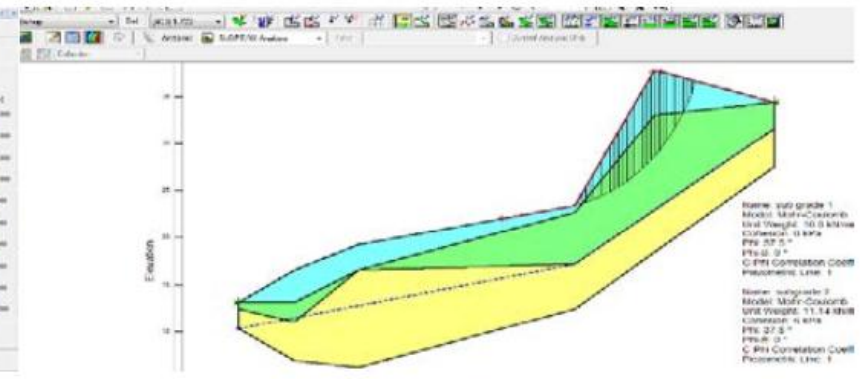

(b)

Fig. 6: Critical failure surfaces obtained from (a) PLAXIS 2D and (b) SLOPE/W analyses using a higher value of cohesion obtained from PBH02. 


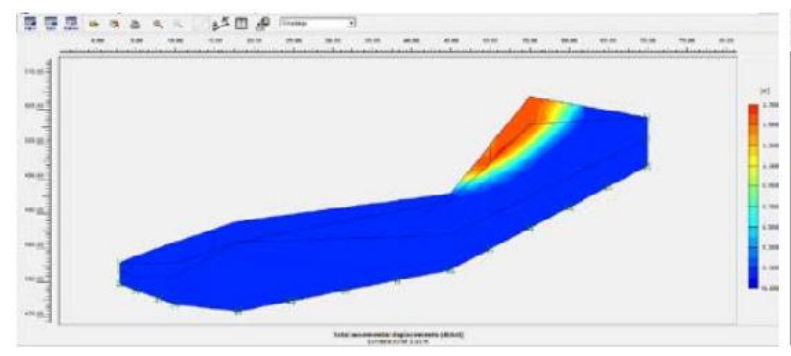

(a)

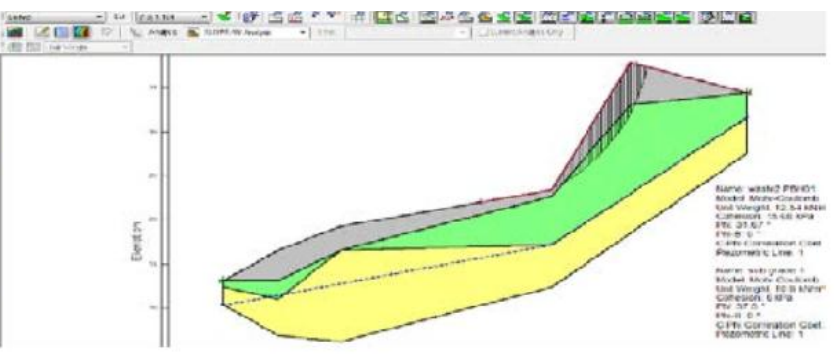

(b)

Fig. 7: Critical failure surfaces obtained from (a) PLAXIS 2D and (b) SLOPE/W analyses using a lower value of cohesion obtained from PBH01.

(c) The existing landfill is found to be stable considering the spatial variation of shear strength properties.

\section{CONCLUSION}

Expansion of waste generation, economy and rapid population growth in particularly among developing nations increased the landfill demands. Inferable from money related limitations, landfills built as a rule endured with the absence of natural reduction measures, for example, leachate assortment frameworks and coating materials. Subsequently, a lot of contamination is incurred upon the environment. It is likewise accepted that weak layers in the landfill brought about via occasional or different elements, or inadequately compacted soil spread layers may have added to the failures. The most significant conclusion is that proprietors and administrators of landfills, be they dump or built, structured landfills should utilize prepared and skilled enough to work their landfills. The administrative or controlling specialists ought to likewise be prepared and proficient. Measures for controlling and expanding ability ought to be presented, if not present. The disposal of MSW by uncompacted revealed end-tipped dumping ought to be eliminated at the earliest opportunity. Where impractical, steeps, hilly regions and especially sites crossed by streams or other watercourses, or situated in marshes or lakes should be avoided.

\section{REFERENCES}

Anderson, J.D. and Wendt J. 1995. Computational Fluid Dynamics. McGraw-Hill, New York, 206.

Bouzza, A. and Wojnarowicz M. 2000. Stability assessment of an old domestic waste slope in Warsaw (Poland). Slope Stability 2000, ASCE GSP No. 101, Proc. of Sessions of GeoDenver, (D.V. Griffiths, G.A. Fenton and T.R. Martin ed.), August 2000, Denver, Colorado, pp. 48-57.

Brandl, H. 1998. Risk analyses, quality assurance, and regulations in landfill engineering and environmental protection. In: (Seco E. Pinto, ed.), Proc. of Environ. Geotech. Balkema Publishers, Rotterdam, pp. 1299-1328.

Fung, Y.C. and Tong, P. 2001. Classical and Computational Solid Mechanics, World Scientific.

Gabr, M.A., Hossain, M.S. and Barlaz, M.A. 2002. Review of shear strength parameters of municipal solid waste with leachate recirculation. Proc. 2nd Intercontinental Landfill Research Symposia, October 2002 in Asheville, North Carolina.

Huvaj-Sarihan, N. and Stark, T.D. 2008. Back analyses of landfill slope failures. In: Proceedings of 6th International Case Histories Conference. Arlington, VA, pp. 11-16.

Isenberg, R.H., Peterson, E. R. and Sternberg, D. 2004. From landfill to leisure: Closure and rehabilitation of Hiriya Landfill. Waste Management World, pp. 45-53.

Kocasoy, G. and Curi, K. 1995. The Umraniye-Hekimbasi open dump accident. Waste Management and Research, 13(4): 305-314.

Koelsch, F., Fricke, K., Mahler, C. and Damanhuri, E. 2005. Stability of landfills-the Bandung dumpsite disaster. In: Sardinia 2005, Tenth International Waste Management and Landfill Symposium. Cagliari, Italy.

Koerner, R.M. and Soong, T.Y. 2000. Stability assessment of ten large landfill failures. Adv. in Transport. and Geoenviron. Systems Using Geosynthetics, ASCE GSP No.103, J. G. Zornberg and B.R. Christopher ed., pp. 1-38.

Liang, H., He, S., Lei, X., Bi, Y., Liu, W. and Ouyang, C. 2019. Dynamic process simulation of construction solid waste (CSW) landfill landslide based on SPH considering dilatancy effects. Bull. Eng. Geol. Environ., 78(2): 763-777.

Liu, G.R. and Gu, Y.T. 2005. An Introduction to Mesh Free Methods and their Programming. Springer, Berlin.

Liu, G.R. and Liu, M.B. 2003. Smoothed Particle Hydrodynamics: A Mesh Free Particle Method. World Scientific.

Liu, M.B. and Liu, G.R. 2010. Smoothed particle hydrodynamics (SPH): An overview and recent developments. Arch. Comput. Methods Engg., 17: 25-76.

Lucy, L.B. 1977. A numerical approach to the testing of the fission hypothesis. Astronom. J., 82: 1013-1024.

Merry, S. M., Kavazanjian Jr, E. and Fritz, W. U. 2005. Reconnaissance of the July 10, 2000, Payatas landfill failure. Journal of Performance of constructed Facilities, 19(2): 100-107.

Mitchell, J.K., Seed, R.B. and Seed, H.B. 1990. Kettleman Hills waste landfill slope failure. I: Liner-system properties. J. Geotech. Eng, 116(4): 647-668.

Ouyang, C., Zhou, K., Xu, Q., Yin, J., Peng, D., Wang, D. and Li, W. 2017. Dynamic analysis and numerical modeling of the 2015 catastrophic landslide of the construction waste landfill at Guangming, Shenzhen, China. Landslides, 14(2): 705-718.

Peng, R., Hou, Y., Zhan, L. and Yao, Y. 2016. Back-analyses of landfill instability induced by high water level: Case study of Shenzhen landfill. Int. J. Env. Res. Pub. He., 13(1): 126.

Prathapan, R., Jeyakaran, T., Thakshajini, L. and Kurukulasuriya, L.C. 2015. Spatial variation of shear strength and consolidation characteristics of a municipal landfill and its implications on the stability of the fill- A Case Study. 3rd International Symposium on Advances in Civil and 
Environmental Engineering Practices for Sustainable Development (ACEPS-2015), Hapugala, Galle, Sri Lanka.

Reddy, K.R. and Bogner, J.E. 2003. Bioreactor landfill engineering for accelerated stabilization of municipal solid waste. Intern. e-Conf. on Modern Trends in Foundation Engg.: Geotechnical Challenges and Solutions, Indian Institute of Technology, Madras.

Sarihan, N.J. and Stark, T.D. 2008. Back-analyses of landfill slope failures. International Conference on Case Histories in Geotechnical Engineering, 12.

Siegel, R.A., Robertson, R.J. and Anderson D.G. 1990. Slope stability investigation at a landfill in Southern California. Geotechnics of Waste Fills - Theory and Practice, ASTM STP 1070, A. Landva and D. Knowles, ed, American Society for Testing and Materials, Philadelphia,
Pennsylvania, pp. 259-284.

Stark, T.D., Arellano, D., Evans, W.D., Wilson, V.L. and Gonda, J.M. 1998. Unreinforced geosynthetic clay liner case history. Geosynth. Int., 5(5): 521.

Stark, T.D., Eid, H.T., Evans, W.D. and Sherry, P.E. 2000. Municipal solid waste slope failure. II: Stability analyses. J. Geotech. Geoenviron. Eng., 126(5): 408-419.

Violeau, D. 2012. Fluid Mechanics and the SPH Method: Theory and Applications. Oxford University Press, Oxford

Yin, Y., Li, B., Wang, W., Zhan, L., Xue, Q., Gao, Y., Zhang, N., Chen, H., Liu, T. and Li, A. 2016. Mechanism of the December 2015 catastrophic landslide at the Shenzhen landfill and controlling geotechnical risks of urbanization. Engineering, 2(2): 230-249. 